\title{
THE INVESTIGATIONS OF ANISOTROPY IN THE ORIENTATIONS OF GALAXIES
}

\author{
W. Godłowski ${ }^{1}$, E. Panko ${ }^{2}$, P. Pajowska ${ }^{3}$, P. Flin ${ }^{4}$ \\ ${ }^{1}$ Uniwersytet Opolski, Institute of Physics, ul. Oleska 48, 45-052 Opole, Poland e-mail: godlowski@uni.opole.pl \\ ${ }^{2}$ Kalinenkov Astronomical Observatory, Mykolaiv State University, Mykolaiv, Ukraine email: panko.elena@gmail.com \\ ${ }^{3}$ Uniwersytet Opolski, Institute of Physics, ul. Oleska 48, 45-052 Opole, Poland e-mail: paoletta@interia.pl \\ ${ }^{4}$ Jan Kochanowski University, Institute of Physics, 25-406 Kielce, ul. Swietokrzyska 15, Poland e-mail: sfflin@cyf-kr.edu.pl
}

(Received January 12, 2012; received in final form August 27, 2012)

\begin{abstract}
In 1994 Parnovsky, Karachentsev and Karachentseva suggested a modified method for the investigation of the orientations of galaxies. Using this method they analyzed galaxies from the UGC and ESO catalogues, as well as from their own catalogue inclusive of flat edge-on galaxies. They found statistically significant anisotropy in the galaxies orientations. In 1995 Flin suggested that this anisotropy has to be specific to Local Supercluster (LSC). In the present paper, using the method proposed by Parnovsky, Karachentsev and Karachentseva in 1994, we analyzed the orientation of galaxies in the sample of galaxies belonging to LSC founding a weak anisotropy only. The relation of this method to Hawley and Peebles (1975) method of the investigation of the orientation of galaxies was discussed as well.
\end{abstract}

Key words: angular momenta, orientations of galaxies.

PACS number(s): 98.65.-r, 98.62.Ai

\section{INTRODUCTION}

The analysis of the anisotropy in galaxy orientation has a long history. Usually two main methods for study of the galaxy orientations' have been introduced. The first one is based on the analysis of the galactic image major axis, i. e. analysis of the galactic position angles was proposed by Hawley and Peebles [1]. Another one based on the idea of Öepik [2], investigates the de-projection of the galaxy images taking into account also the galaxy's inclination with respect to the observer's line of sight $i$. This method was applied by Jaaniste \& Saar [3] and significantly modified by Flin \& Godłowski [4-7] (see also [8]).

In 1994 Parnovsky, Karachentsev and Karachentseva [9] suggested a new method for investigating the distribution of the orientations of galaxies. This method was in fact simply a modification of the Hawley's and Peebles's [1] approach. Parnovsky, Karachentsev and Karachentseva processed the data from the UGC [10] and ESO [11] catalogues, and from their own catalogue inclusive of flat edge-on galaxies (FGC) [12]. They detected statistically significant anisotropy in the orientation of galaxies. They described the orientation distribution by a three-axis ellipsoid, showing an excess of about $20 \%$ in the direction $4^{h}-6^{h}, 20^{\circ}-40^{\circ}$, and a deficit of about $25 \%$ in the direction $13^{h}-15^{h}, 30^{\circ}-40^{\circ}[9]$. The authors recognized that this observed anisotropy has a global character, at least in the sense of the survey extend. This was generally consistent with the earlier results of Fliche and Soriau [13] concerning the orientation of extended galactic HI envelopes and the "cosmic pole" detected in the analysis of remote quasars $\left(5^{h} 30^{m}, 7^{\circ}\right)$. Later, Flin [14] analyzed their results and argued that these results indicated that the observed anisotropy is consistent with the results obtained previously by Flin and Godłowski [4] and has not got a global character, instead was connected with the alignment of galaxies in LSC.

The method of Parnovsky, Karachentsev and Karachentseva [9] was rather neglected in the future papers with one exception of the Parnovsky et al. analysis of the orientation of galaxy pairs [15]. In the present paper we decided to use the method proposed in [9] for analysing a sample of galaxies belonging to the LSC and finding a weak possible alignment only. The aim of our paper is repeat the Parnovsky, Karachentsev and Karachentseva [9] investigation using their method on the samples of galaxies with certain membership of Local Supercluster.

\section{OBSERVATIONAL DATA}

In our work we studied the 2D-projected alignment of the galaxies in the LSC. A sample of galaxies was taken from Tully's Nearby Galaxies (NBG) Catalogue [16]. This Catalogue contains 2367 galaxies with radial velocities less than $3000 \mathrm{kms}^{-1}$. Tully's Catalogue provides a relatively uniform coverage of the entire unobscured sky [17]. Galaxies position angles were taken from $[10,11,18,19]$, while some missing measurements were made on PSS prints by Piotr Flin [7]. The galaxies distances were very well and in a uniform manner determined. As a result, the lists of galaxies were free from the background objects. It is crucial in such a type of the analysis.

\section{METHODS OF THE INVESTIGATIONS}

The idea of the Parnovsky, Karachentsev and Karachentseva [9] method is the analysis of the distribution of the position angles in different coordinate systems. They assumed the equatorial coordinate system as 
a fundamental coordinate system and later the position of the coordinate system pole was varied, both in $\alpha$ and $\delta$. Our interest is to find the position angles $p^{\prime}$ in a particular coordinate system with respect to a pole at $\left(\alpha_{p}, \delta_{p}\right)$. The Parnovsky, Karachentsev and Karachentseva function $F$ is defined as follows [9]:

$$
F(\alpha, \delta) \equiv \frac{4}{N} \sum_{k=0}^{179} N_{k} \cos 2 p_{k}^{\prime},
$$

where $N_{k}$ is a number of galaxies with position angle $p^{\prime}$. The variance of $F$ is given by formula [15]:

$$
\sigma^{2}(F)=8 N^{-1}(179 / 180)^{2} .
$$

However, one should note that analyzed in [9] Function $F$ is a special case of Hawley and Peebles [1] Fourier Test. The idea of this test is as follows. If the deviation from isotropy is a slowly varying function of the angle $\theta$ (in our case $\theta=p^{\prime}$ ) then,

$$
N_{k}=N_{0, k}\left(1+\Delta_{11} \cos 2 \theta_{k}+\Delta_{21} \sin 2 \theta_{k}\right)
$$

and we obtain the following expressions for the $\Delta_{i 1}$ coefficients $[5,6,20,21]$ :

$$
\begin{aligned}
& \Delta_{11}=\frac{\sum_{k=1}^{n}\left(N_{k}-N_{0, k}\right) \cos 2 \theta_{k}}{\sum_{k=1}^{n} N_{0, k} \cos ^{2} 2 \theta_{k}}, \\
& \Delta_{21}=\frac{\sum_{k=1}^{n}\left(N_{k}-N_{0, k}\right) \sin 2 \theta_{k}}{\sum_{k=1}^{n} N_{0, k} \sin ^{2} 2 \theta_{k}} .
\end{aligned}
$$

where $N_{k}$ is the number of galaxies with orientations within the $k$-th angular bin, while $N_{0, k}$ denotes the expected number of galaxies in the $k$-th bin. In the case of analysing the distribution of the position angles all $N_{0, k}$ are equal $N_{0}$, which is also the mean number of galaxies per bin. It is easy to see that Function $F$ is in this case is strictly related to $\Delta_{11}$ coefficient: $F=2 \Delta_{11}$ (see $[21,22]$ for details).

In our paper instead of the equatorial coordinate system we used another, supergalactic coordinate system (Flin and Godłowski [4]) as a fundamental coordinate system, and the position of the coordinate system pole was varied (by $5^{\circ}$ at a time), both in supergalactic latitude $B$ and longitude $L$.

\section{THE RESULTS}

Our main results were presented on Figs. 1-3. On Fig. 1 we presented Function $F[9]$ for galaxies from Tully's NGC Catalogue depending on morphological types, while the results for Fig. 2 were restricted only for galaxies with reliably measured position angles. On every map we presented the value of the analyzed function $F$ with respect to the chosen cluster pole, divided by its formal error $\sigma(F)$. In other words, the parameters $f=F / \sigma(F)$ were mapped. The cluster pole coordinates change along the entire celestial sphere. The resulting maps were analyzed for the correlations of their maxima with important points on the maps. The maximum in $f$ function means that we have an excess of galaxies with position angles pointing in this direction. The minimum in $f$ function denotes a deficit of galaxies with position angles pointing in the particular direction. There is a clear interpretation for edge-on galaxies - minimum in position angles means an excess of normal to galaxy plane (taken as rotation axis of galaxies) pointing in the analyzed direction.
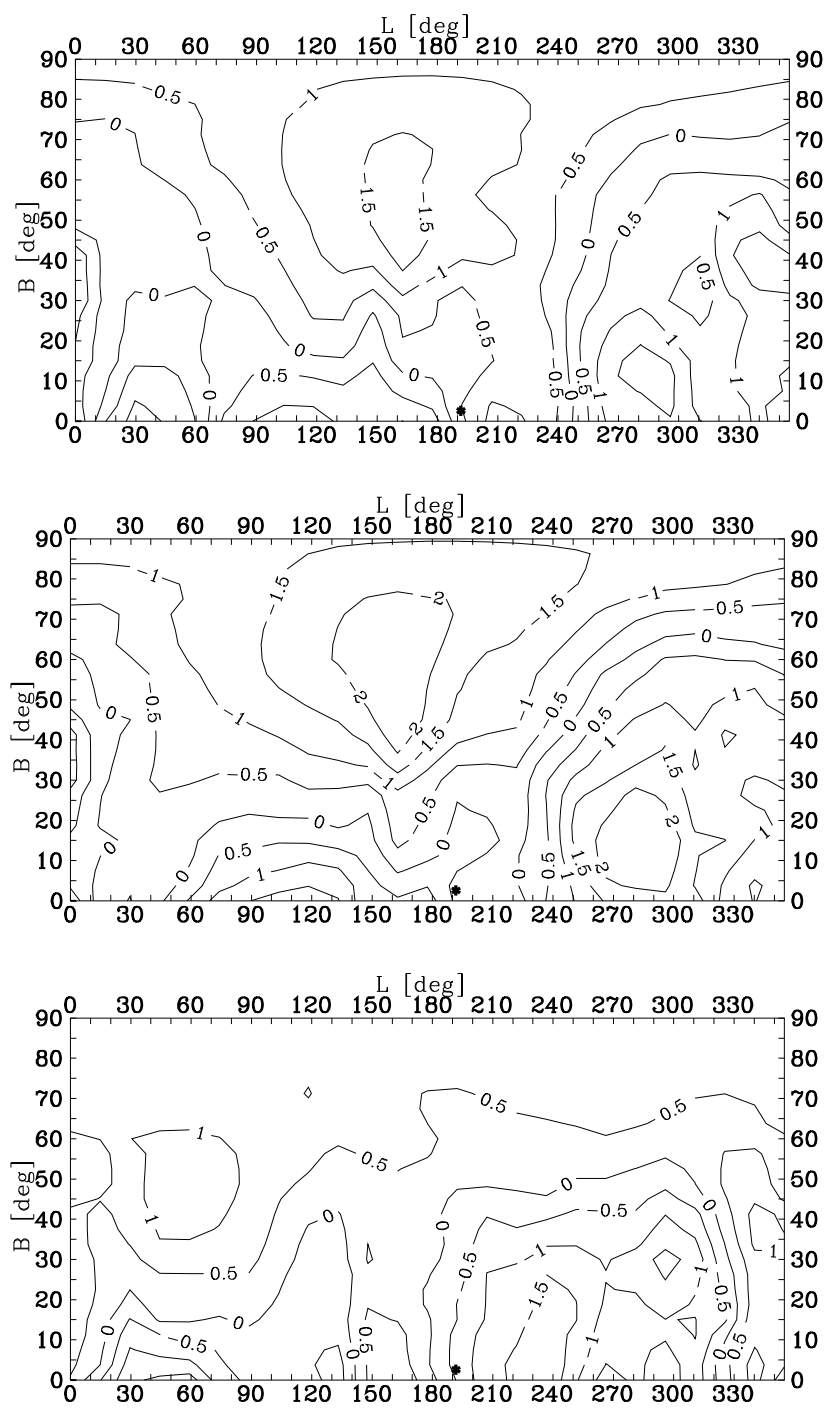

Fig. 1. Maps of $f \equiv F / \sigma(F)$ versus the chosen cluster pole in supergalactic coordinates $(L, B)$ for NGC galaxies. The maps are presented for ALL galaxies (upper panel), for $\mathrm{S}$ (middle panel) and NS (bottom panel) sub-samples. On the map we indicated the important position, the direction to the Local Supercluster centre (point).

One can see from Fig. 1, that only for spiral galaxies (S) we obtained the $2 \sigma$ extremum. Maximum is pointed near to the Local Supercluster plane in the longitude $L$ of about $L=270^{\circ}$, while minimum is pointed to the direction perpendicular to the LSC plane. If we restricted 
our sample to the galaxies with certainly measured position angles (Fig. 2) the result was similar but the effect is much stronger, i.e. we observed $2 \sigma$ extremum even for all galaxies. Separately we analyzed a sample of 2227 UGC/ESO galaxies [5,6] (Fig. 3). The results for that sample were the same as for NGC galaxies but positive extremum for all and spiral galaxies is on $3 \sigma$ level.
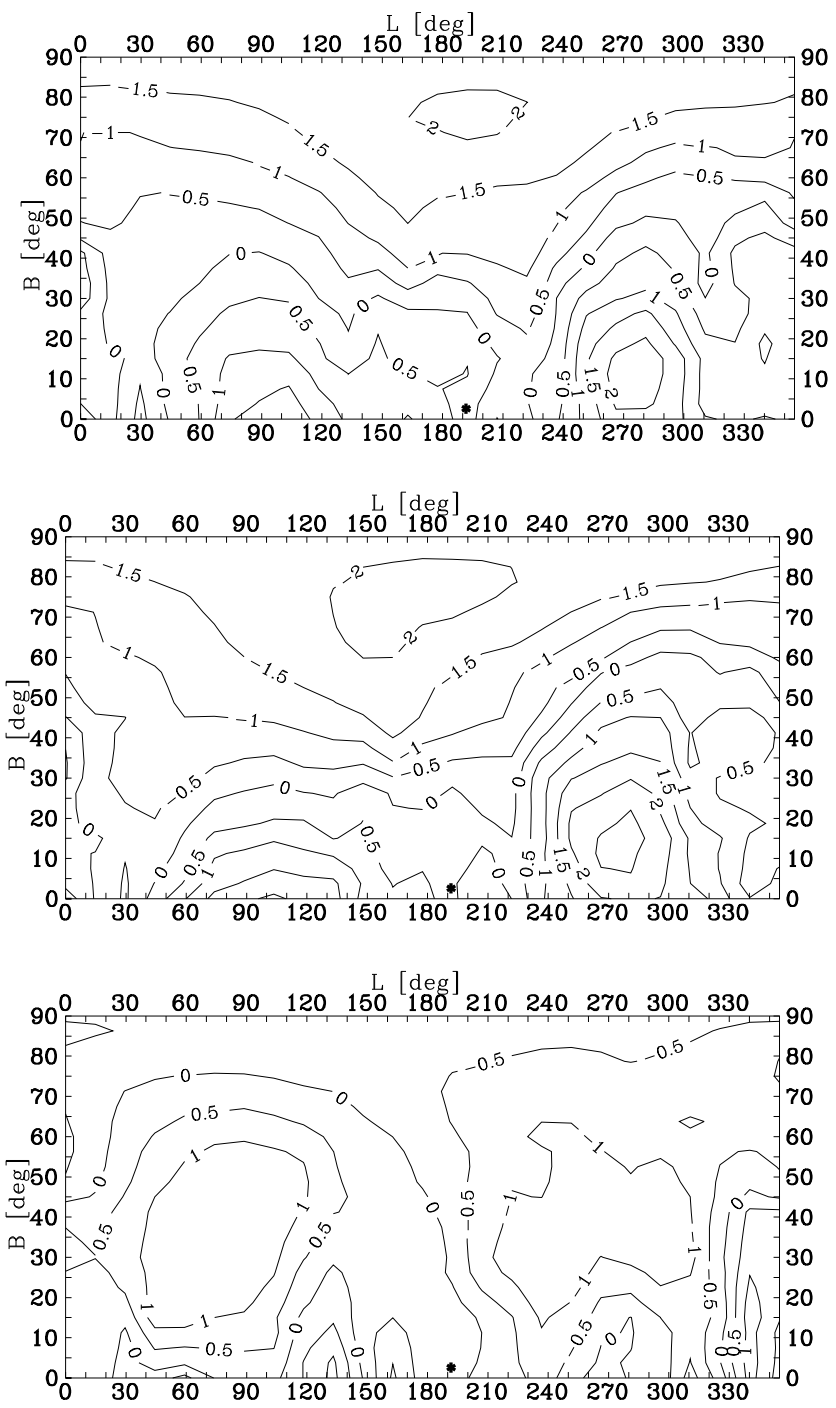

Fig. 2. The maps of $f \equiv F / \sigma(F)$ versus the chosen cluster pole in supergalactic coordinates $(L, B)$ for NGC galaxies with reliably measured position angles. The maps were presented for ALL galaxies (upper panel), for S (middle panel) and NS (bottom panel) sub-samples. On the map we indicated the important position, the direction to the Local Supercluster centre (point).

Our results - the minimums of $f$ function in the direction perpendicular to the LSC plane for spiral galaxies (S) - are in agreement with the results obtained by Aryal and Saurer [23], who found a weak preference of spin directions for the spiral galaxies belonging to the Local Supercluster. They found that the spin vector orientations of the spiral galaxies in the LSC tend to be oriented perpendicular to the LSC plane.
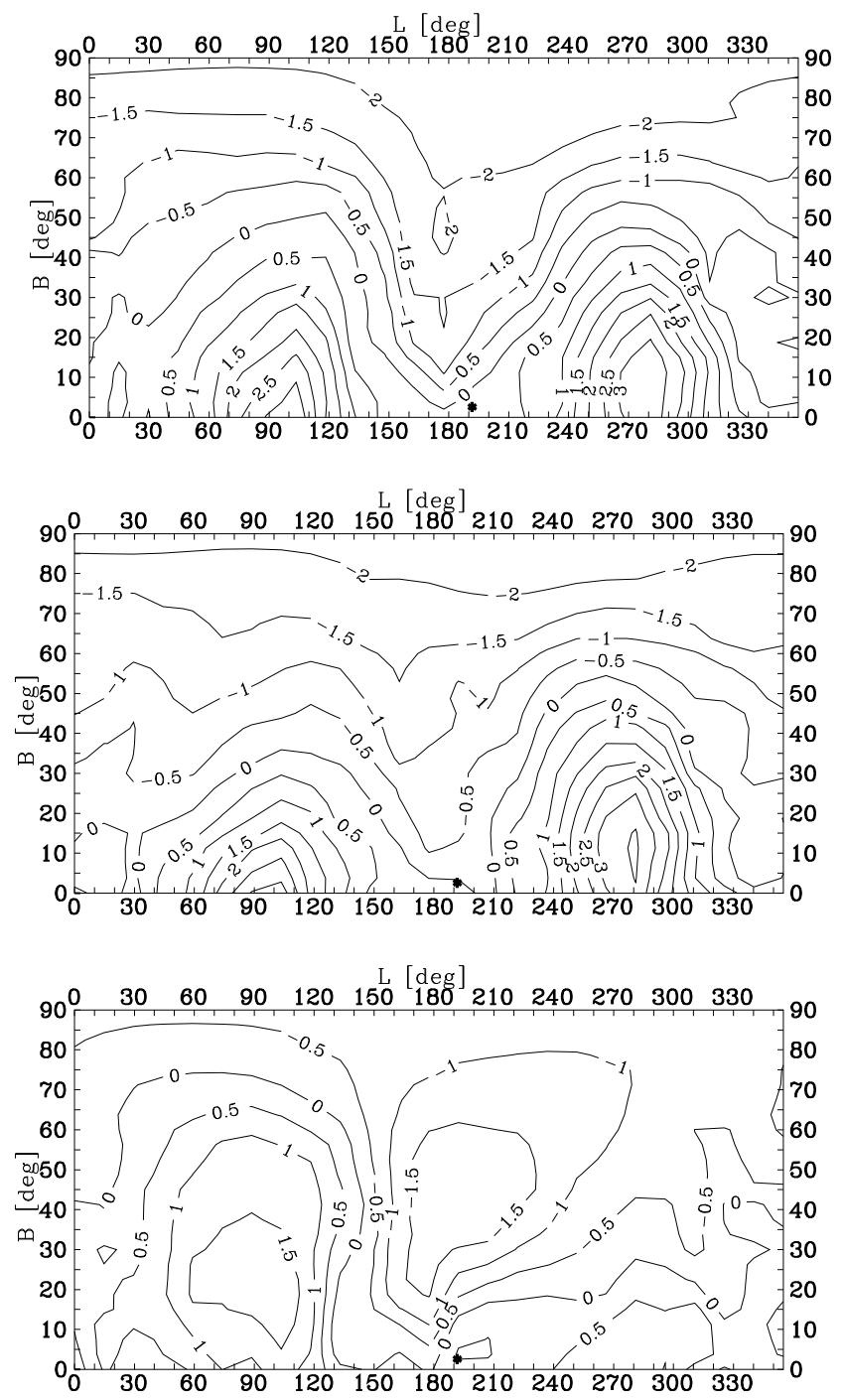

Fig. 3. The maps of $f \equiv F / \sigma(F)$ versus the chosen cluster pole in supergalactic coordinates $(L, B)$ for UGC/ESO galaxies. The maps were presented for ALL galaxies (upper panel), for S (middle panel) and NS (bottom panel) sub-samples. On the map we indicated the important position and the direction to the Local Supercluster centre (point).

\section{DISCUSSION AND CONCLUSIONS}

We analyzed a sample of galaxies belonging to the Local Supercluster using Function $F$ proposed by Parnovsky, Karachentsev and Karachentseva [9]. We found an excess of galactic position angles pointing to the LSC plane in the direction of about $270^{\circ}$ and a deficit of galaxies with the position angles perpendicular to the LSC plane. This effect is a weak one and connected with spiral galaxies. Our results are in agreement with Aryal and Saurer [23] suggestion, who found a weak preference of galactic spins for spiral galaxies, in the direction perpendicular to the LSC plane.

In our opinion the function proposed in [9] is useful but using the full Peebles Fourier test (see for example $[1,4-8,23-25])$ being more adequate because of ex- 
ploring not only Peebles coefficient $\Delta_{11}$ but complete information connected with a slowly varied function of angle $\theta, N_{k}=N_{0, k}\left(1+\Delta_{11} \cos 2 \theta_{k}+\Delta_{21} \sin 2 \theta_{k} \ldots\right)$.

The possibility of the existence of a large-scale alignment suggested by Parnovsky et al. [9] needs more studies in the future. Recently some other papers implied such possibilities. Paz, Stasyszyn and Padilla [26] analyzing galaxies from the Sloan Digital Sky Survey Catalogue found that the galaxy's angular momenta are aligned perpendicularly to the planes of large-scale structures, while there is no such an effect for the small-scale structures. They interpret this as consistent with their simulations based on the mechanism of tidal interactions. Jones, van der Waygaert and Aragon-Calvo [27] found that the spins of spiral galaxies located within cosmic web filaments tend to be aligned along the larger axis of the filament, which they interpret as "fossil" evidence indicating that the action of large scale tidal torques affected the alignments of galaxies located in cosmic filaments.

The evidence for the structural anisotropy of the small-large galaxy structures inside of the deep-field surveys likely for example the Jagellonian field [28], was presented in [29], where the method of the effective ellipse of inertness was applied [30]. The statistically significant anisotropy for the galaxy groups and clus- ters orientations inside the cone of the Jagellonian field $R \sim 3000 \mathrm{Mpc}$ is in the range 105-120 deg. [29]. It also should be noticed that Mandzhos et al. [31,32], during the analysis of UGC [10] (north hemisphere) and ESO [11] (south hemisphere) galaxies, found that galaxies major axes are distributed anisotropically.

Other possibilities of a large-scale alignment were found in the series of papers by Hutsemekers [33-35] from analysis of the alignment of quasar polarization vectors. In the paper Hutsemekers et al. [33] based on a sample of 355 quasars with a significant optical polarization they found that quasar polarization vectors are not randomly oriented over the sky. The polarization vectors appear to be coherently oriented or aligned over huge $(\sim 1 \mathrm{Gpc})$ regions at the sky. Furthermore, the mean polarization angle $\theta$ appears to rotate with redshift at the rate of $\sim 30^{\circ}$ per Gpc. While interpretations like a global rotation of the Universe can potentially explain the effect of the properties they observed qualitatively correspond to the dichroism and birefringence predicted by the photon-pseudoscalar oscillation within a magnetic field. The origin of this results is still discussed and possible interpretations were provided for example by Hutsemekers [34-36] and recently by Agarwal, Kamal and Jain [37].
[1] D. I. Hawley, P. J. E. Peebles, Astron. J. 80, 477 (1975).

[2] E. J. Öepik, Irish Astron. J. 9, 211 (1970).

[3] J. Jaaniste, E. Saar, in The large scale structures of the Universe, edited by M. S. Longair, J. Einasto, D. Reidel, (Dordrecht, IAU Symp. 79, 1978), p. 488.

[4] P. Flin, W. Godłowski, Mon. Not. R. Astron. Soc. 222, 525 (1986).

[5] W. Godłowski, Mon. Not. R. Astron. Soc. 265, 874 (1993).

[6] W. Godłowski, Mon. Not. R. Astron. Soc. 271, 19 (1994).

[7] W. Godłowski, P. Flin, Astrophys. J. 708, 902 (2010).

[8] B. Aryal, W. Saurer, Astron. Astrophys. 364, L97 (2000).

[9] L. S. Parnovsky, I. D. Karachentsev, V. Karachentseva, Mon. Not. R. Astron. Soc. 268, 665 (1994).

[10] P. Nilson, Uppsala General Catalogue of Galaxies, Astr. Obs. Ann. V, Vol. 1 (Uppsala, 1973).

[11] A. Labuerts, ESO/UppsalaSurvey of the ESO B Atlas (ESO, Garching, 1982).

[12] I. D. Karachentsev, V. E. Karachentseva, L. S. Parnovsky, Astron. Nachr. 314, 97 (1993).

[13] H. H. Fliche, J. M. Souriau, Astron. Astrophys. 233, 317 (1990).

[14] P. Flin, Comm. Astrophys. 18, 81 (1995).

[15] L. S. Parnovsky, Yu. N. Kudrya, I. D. Karachentsev, Astron. Lett. 23, 504 (1997).

[16] R. B. Tully, Nearby Galaxy Catalog (Cambridge,1988).

[17] R. B. Tully, Astrophys. J. 321, 280 (1987).

[18] P. Nilson, Catalogue of Selected Non-UGC Galaxies, Uppsala Astr. Obs. Rep. 5 (Uppsala, 1974).
[19] A. Lauberts, E. Valentijn, The Surface Photometry Catalogue of the ESO-Uppsala Galaxies (ESO, Garching, 1989).

[20] W. Godłowski, P. Piwowarska, E. Panko, P. Flin, Astrphys. J. 723, 985 (2010).

[21] W. Godłowski, Astrophys. J. 747, 7 (2012).

[22] P. Pajowska, W. Godłowski, E. Panko, P. Flin, J. Phys. Stud. 16 (in press, 2012).

[23] B. Aryal, W. Saurer, Astron. Astrophys. 432, 431 (2005).

[24] B. Aryal, R. K. Bachchan, W. Saurer, Bull. Astron. Soc. India 38, 165 (2010).

[25] B. Aryal, Res. Astron. Astrophys. 11, 293 (2011); preprint: arXiv 1010.5585 (2010).

[26] D. J. Paz, M. A. Sgró, M. Merchan, N. Padill, Mon. Not. R. Astron. Soc. 414, 2029 (2011).

[27] B. Jones, R. van der Waygaert, M. Aragon-Calvo, Mon. Not. R. Astron. Soc. 408, 897 (2010).

[28] P. Flin, I. B. Vavilova, in Proceedings of the 27th Meeting of the Polish Astronomical Society, Poznan, September 12-15, 1995, edited by M. J. Sarna, P. B. Marks (Poznan, 1996), p. 63.

[29] A. Ja. Gregul, A. V. Mandzhos, I. B. Vavilova, Astrophys. Space Sci. 185, 223 (1991).

[30] I. B. Vavilova, Kinem. Phys. Celest. Bodies 15, 69 (1999).

[31] A. V. Mandzhos, V. V. Tel'nyuk-Adamchuk, A. Ya. Gregul', Sov. Astron. Lett. 11, 206 (1985).

[32] A. V. Mandzhos, A. Ya. Gregul', I. Yu. Izotova, V. V. Tel'nyuk-Adamchuk, Astrofizika 26, 321 (1987).

[33] D. Hutsemekers, Astron. Astrophys. 332, 410 (1998). 
[34] D. Hutsemekers, H. Lamy, Astron. Astrophys. 367, 381 (2001).

[35] D. Hutsemekers, R. Cabanac, H. Lamy, D. Sluse, Astron. Astrophys. 441, 915 (2005).
[36] D. Hutsemekers, B. Borguet, D. Sluse, R. Cabanac, H. Lamy, Astron. Astrophys. 520, L7 (2010).

[37] N. Agarwal, A. Kamal, P. Jain, Phys. Rev. D. 83, 065014 (2011)

\title{
ДОСЛІДЖЕННЯ АНІЗОТРОПІЇ ОРІЕНТАЦІї ГАЛАКТИК
}

\author{
В. Годловскі ${ }^{1}$, О. Панько ${ }^{2}$, П. Пайовска ${ }^{3}$, П. Флін ${ }^{4}$ \\ ${ }^{1}$ Інститут фізики Опольсъкого університету, \\ вул. Олесъка, 48, 45-052, Ополе, Польща \\ ${ }^{2}$ Астрономічна обсерваторія імені Каліненкова, Миколаӥвсъкий державний університет, \\ Миколаїв, Україна \\ ${ }^{3}$ Інститут фізики Опольсъкого університету, \\ вул. Олесъка, 48, 45-052, Ополе, Польща \\ ${ }^{4}$ Інститут фізики Університету імені Яна Кохановсъкого, \\ вул. Свентокшиска, 15, 25-406, Кельче, Польща
}

У 1994 році Л. Парновський, І. Караченцев і В. Караченцева запропонували модифікований метод для дослідження орієнтації галактик. Використовуючи його, вони проаналізували галактики з каталогив UGC та ESO, а також зі свого власного каталогу, що включає плоскі, видимі з ребра галактики. Вони виявили статистично значущу анізотропію в орієнтації галактик. У 1995 році П. Флін припустив, що ця анізотропія має бути характерною для Місцевого Надскупчення (МНС). У цій статті, використовуючи згаданий метод, ми проаналізували орієнтацію галактик, що належать до МНС, і знайшли лише слабку анізотропію. Ми також обговорюємо зв'язок цього методу з методом дослідження орієнтації галактик Хоулі та Піблса (1975). 